\title{
O Processo de Elaboração dos Planos de Ação em Governo Aberto do Município de São Paulo, SP, Brasil
}

The Process of Preparing Action Plans in the Open Government of the Municipality of São Paulo, SP, Brazil

El Proceso de Preparación de Planes de Acción en el Gobierno Abierto del Municipio de São Paulo, SP, Brasil

Le Processus de Préparation des Plans d'Action dans le Gouvernement Ouvert de la Municipalité de São Paulo, SP, Brésil

\footnotetext{
${ }^{1}$ Especialista em Gestão Pública pela Universidade Federal de São Paulo, São Paulo, SP, Brasil. Atua junto à Prefeitura de São Paulo, SP, Brasil, na Secretaria de Governo Municipal -junto ao serviço de Supervisão para Assuntos de Governo Aberto.

E-mail: fernandalima01@ hotmail.com

${ }^{2}$ Graduado em Comunicação Social pela Universodade Paulista e em Gastronomia pela Universidade Anhembi Morumbi e especialista em em Marketing do Varejo pelo Centro Universitário "Serviço Nacional de Aprendizagem Comercial", São Paulo, SP, Brasil. É mestre em Hospitalidade pela Universidade Anhembi Morumbi e doutorando pelo Programa de Pós-Graduação Interunidades Integração América Latina da Universidade de São Paulo, São Paulo Brasil. Atualmente é professor no Centro Universitário "Serviço Nacional de Aprendizagem Comercial" nos cursos de graduação e pós-graduação em Gastronomia e professor no curso de especialização em Gestão Pública da Universidade Federal de São Paulo, São Paulo, SP, Brasil. 
Resumo

Abstract

Resumen
$\mathrm{O}$ artigo apresenta brevemente o conceito de governo aberto e a sua implementação na Prefeitura de São Paulo, o que culminou com o ingresso do município na Parceria para Governo Aberto (OGP - tradução de Open Government Partnership), resultando no processo de construção dos primeiro e segundo planos de ação em Governo Aberto, em 2016 e 2018, respectivamente. Em seguida, estabeleceu-se um comparativo entre os Planos, com destaque aos pontos de amadurecimento do processo, bem como de incongruências entre os atores envolvidos, a fim de conjecturar o quanto alguns elementos das metodologias utilizadas influenciaram no teor dos compromissos construídos e assumidos pela Prefeitura. Baseado, essencialmente, em documentos que tratam do processo de construção (planos de ação e relatório de avaliação) disponibilizados pela Prefeitura de São Paulo e pela OGP, o artigo também faz considerações acerca de questões metodológicas passíveis de discussão e reformulação.

Palavras-chave: Governo Aberto; Plano de Ação em Governo Aberto; Fórum de Gestão Compartilhada; Processo Participativo; Política Pública.

This paper briefly presents the open government concept and its implementation in São Paulo city hall, which ended up in the entrance of the municipality in the OGP - Open Government Partnership -, resulting in the construction of the $1^{\text {st }}$ and $2^{\text {nd }}$ Open Government Action Plans, in 2016 and 2018, respectively. Next, a comparison has been made between the Plans, with a highlight on the points of the process maturation, as well as of incongruities among the engaged actors, in order to conjecture at what extent some features within the adopted methodologies influenced in the content of the commitments built and assumed by the city hall. Based essentially on documents related to the construction process (action plans and assessment report), made available by São Paulo prefecture and by the OGP, the paper also points out some remarks on the methodological issues subject to be discussed and reformulated..

Keywords: Open Government; Open government Action Plan; MultiStakeholder Forum; Participatory Process; Public Policy.

El artículo presenta de manera breve el concepto de Gobierno Abierto y su implementación en el Ayuntamiento de São Paulo, lo que culminó con su ingreso en la Alianza para Gobierno Abierto (OGP por sus siglas en inglés) y que a su vez, resultó en el proceso de construcción del 1er y 2do Plan de Acción en Gobierno Abierto, en 2016 y 2018, respectivamente. A continuación, se establece un comparativo entre los Planes, con atención a los puntos de maduración del proceso, y también a las incongruencias entre los actores involucrados, a fin de conjeturar el cuanto algunos elementos de las metodologías utilizadas influyeron en el contenido de los compromisos construidos y asumidos por el ayuntamiento. Basado, esencialmente, en documentos que tratan del proceso de construcción (planes de acción e informes 
de evaluación) publicados por el Ayuntamiento de São Paulo y OGP, el artículo también trae consideraciones acerca de cuestiones metodológicas susceptibles de discusión y reformulación.

Palabras-clave: Gobierno Abierto; Plan de Acción en Gobierno Abierto; Foros Multisectoriales; Proceso Participativo; Política Pública.

Résumé L'article présente brièvement le concept de gouvernement ouvert et sa mise en œuvre dans la municipalité de São Paulo, qui a abouti à l'adhésion de la municipalité au Partenariat pour un gouvernement ouvert (OGP - traduction de Open Government Partnership), aboutissant au processus de construction du premier et selon les plans d'action pour un gouvernement ouvert, respectivement en 2016 et 2018. Ensuite, une comparaison a été faite entre les Plans, en mettant l'accent sur les points de maturité du processus, ainsi que sur les incohérences entre les acteurs impliqués, afin de conjecturer à quel point certains éléments des méthodologies utilisées ont influencé le contenu des engagements construits et assumés par l'entreprise. Mairie. Essentiellement basé sur des documents traitant du processus de construction (plans d'action et rapport d'évaluation) mis à disposition par la ville de São Paulo et par l'OGP, l'article fait également des réflexions sur les questions méthodologiques qui peuvent être discutées et reformulées.

Mots-clés: Gouvernement Ouvert; Plan d'Action pour un Gouvernement Ouvert; Forum de Gestion Partagée; Processus Participatif; Politique Publique. 


\section{Introdução}

A definição de Governo Aberto ainda não encontra um consenso entre os estudiosos, pois é um conceito construído a partir de temas diversos. No entanto, segundo Calderón e Lorenzon (2010:11) há um entendimento na doutrina de que, essencialmente, trata-se de uma

evolução do nosso sistema democrático de convivência e valores baseado no estabelecimento de mecanismos para a transparência dos governos assim como dos espaços permanentes de colaboração e participação dos cidadãos mais além do exercício do direito ao voto a cada quatro anos. (Calderón \& Lorenzon, 2010:11)

Assim, as suas variadas significações estão relacionadas à transversalidade dos temas/valores que o compõem, entre os quais: participação cidadã, acesso à informação, prestação de contas (accountability), inovação, transparência e abertura de dados. (Bellix, Guimarães \& Machado, 2016).

Em 2009, com a publicação de um memorando pelo governo dos Estados Unidos (US Government, 2009), o conceito ganha notoriedade e, a partir de 2011, passa a ser mais amplamente difundido com a criação da Parceria para Governo Aberto (OGP) - tradução de Open Government Partnership - e da disseminação da Declaração de Governo Aberto (OGP, 2011).

Atualmente, mais de setenta países firmaram o compromisso de concretizar ações por meio da OGP, objetivando tornar seus governos mais íntegros, transparentes, participativos e inovadores por meio da elaboração de planos de ação contendo compromissos que devem ser implementados no período de dois anos.

Em 2016, com o entendimento de que mudanças mais efetivas ocorrem em âmbito local, a OGP lançou o programa piloto para governos subnacionais com a participação inicial de 15 governos locais (estados, províncias e municípios), entre eles o município de São Paulo. Em decorrência da entrada de São Paulo na OGP, foi elaborado, ainda em 2016, o Plano de Ação da cidade de São Paulo (doravante 1o Plano de Ação em Governo Aberto do município de São Paulo) composto por cinco compromissos que foram implementados em 2017. Em 2018, iniciou-se o processo de elaboração do $2^{\circ}$ Plano de Ação, também com cinco compromissos a serem executados entre janeiro de 2019 e agosto de 2020.

Por diretrizes da OGP, em consonância com os valores de governo aberto, o processo de elaboração dos planos de ação, tanto nacional, quanto subnacional, deve ser participativo. Por essa razão, para ambos os planos, São Paulo instituiu o Fórum de Gestão Compartilhada (FGC), órgão colegiado formado por representações do governo e

\footnotetext{
${ }^{1}$ Tradução livre de Calderón \& Lorenzon (2010, p. 11).
} 
da sociedade civil, cujas atribuições são coordenar o processo de elaboração do plano de ação, acompanhar e atuar na sua execução e avaliação.

A composição do FGC, instituído em 2018, conta com representações de oito secretarias municipais e oito entes da sociedade civil - a composição de 2016 possuía uma secretaria e oito organizações da sociedade civil. Não é surpreendente que um colegiado com esta composição, mesmo que construído para um objetivo comum, possua entendimentos e motivações distintas de envolvimento, porém, como convém a políticas públicas formuladas de forma participativa, os diferentes pontos de vista agregam valor ao processo de elaboração, aumentando o seu potencial de efetividade.

Como resultado, o estudo apresenta um panorama do processo de construção dos $1^{\text {o }}$ e do $2^{\circ}$ Planos de Ação em Governo Aberto do município de São Paulo, com destaque aos elementos que contribuíram para o enriquecimento do processo, sobretudo do ponto de vista da participação social, mas também com considerações acerca da assunção da pauta por parte da Prefeitura de São Paulo.

Para tal, a autora, servidora pública atuante em todo o processo do $2^{\circ}$ Plano de Ação, adotou a técnica da observação participante e da pesquisa documental. Esta última, referente a ambos os processos. Espera-se que o presente artigo ofereça reflexões acerca dos processos de construção anteriores, visando aprimoramentos para a construção de um terceiro plano de ação, bem como que possa contribuir também para a elaboração de políticas semelhantes por outros municípios.

\section{O Conceito de Governo Aberto e o Ingresso do Município de São Paulo na Parceria para Governo Aberto (OGP)}

Para além das diferentes conceitualizações a respeito de governo aberto, para CruzRubio (2015), trata-se de um paradigma em expansão e pode ser apreendido tanto como um modo de governança quanto como estratégia ou modo de atuar do governo. Após desenvolver análise de definições prévias do conceito, ele propõe a seguinte definição:

definimos governo aberto como uma filosofia político-administrativa, um novo paradigma ou modelo de interação sociopolítica que - baseada firmemente nos valores e princípios de transparência, de democracia participativa e empoderamento cidadão, de prestação de contas, de open data e do uso de inovações tecnológicas, e na conformação de governos como plataformas que promovam a colaboração e interação - se constitui como um modo e / ou estratégia para o desenho, implementação, controle e avaliação de políticas públicas e para processos de modernização administrativa, e que coloca o cidadão como centro de atenção e prioridade, oferecendo assim uma alternativa para a gestão pública. Como filosofia político-administrativa, é pois 
diferenciável em relação a outras estratégias ou filosofias políticoadministrativas existentes (Cruz-Rubio, 2015:145).

A maioria das definições analisadas nesse estudo são posteriores à publicação do memorando do governo dos Estados Unidos (US Government, 2009) e da disseminação da Declaração de Governo Aberto (OGP, 2011). No primeiro documento, a definição do conceito é entendida como o incentivo à realização de ações relacionadas a três pilares essenciais: transparência; participação e colaboração. No segundo, os países signatários se comprometem a fomentar governo aberto por meio de ações em quatro pilares fundamentais: transparência; participação cidadã; integridade (accountability) e inovação e tecnologia.

Em 20 de setembro de 2011, eram oito os entes fundadores da OGP - África do Sul, Brasil, Estados Unidos, Filipinas, Indonésia, México, Noruega e Reino Unido. 0 Brasil presidiu o Comitê Diretor no primeiro ano. Em 2019, 79 países, além de 20 governos subnacionais, integravam a OGP, resultando no expressivo número de mais de 4000 compromissos criados com o objetivo de tornar diversos governos ao redor do mundo mais abertos e responsáveis (OGP, 2019).

Os governos locais ingressaram na OGP a partir do Programa Piloto para Governos Subnacionais, em 2016, em um ato de reconhecimento de que muitas das mudanças significativas, como maior sucesso em engajamento cidadão e entrega de serviços, ocorrem localmente.

O mérito da escolha do município de São Paulo está no fato de este já desenvolver ações de governo aberto, como a criação da Controladoria Geral do Município (CGM), da São Paulo Aberta e do Comitê Intersecretarial de Governo Aberto da Cidade de São Paulo (CIGA-SP) ${ }^{2}$, respectivamente em 2013 e 2014, e também pelo bom posicionamento da cidade na Escala Brasil Transparente elaborada pela Controladoria Geral da União (CGU), a fim de medir a transparência pública em estados e municípios brasileiros ${ }^{3}$.

Assim, no Global OGP Summit, realizado em Paris, em dezembro de 2016, a Prefeitura de São Paulo assinou a Declaração Subnacional de Governo Aberto e submeteu o seu Plano de Ação, corroborando o interesse do município em consolidar a agenda de governo aberto.

${ }^{2}$ A São Paulo Aberta foi instituída em 2014, a partir do Decreto n ${ }^{\circ}$ 54.794, no âmbito da Secretaria Municipal de Relações Internacionais, como iniciativa responsável por fomentar o desenvolvimento e a integração de iniciativas de governo aberto na Prefeitura de São Paulo. Em 2018, com a publicação do Decreto ${ }^{\circ}$ 58.162, a São Paulo Aberta tornou-se Supervisão para Assuntos de Governo Aberto (SAGA). Em 2019, por meio do Decreto $n^{\circ}$ 58.596, a área foi transferida para a Secretaria de Governo Municipal.

${ }^{3}$ Fonte: https://www.gov.br/cgu/pt-br/assuntos/transparencia-publica/escala-brasil-transparente. Acesso em 23 de julho de 2020. 


\section{A Construção do Primeiro Plano de Ação em Governo Abero}

A Prefeitura de São Paulo, com a instituição da São Paulo Aberta e do CIGA-SP, em 2014, adotou os pilares de governo aberto definidos pela OGP, acompanhando, fomentando e articulando, por meio da agora Supervisão para Assuntos de Governo Aberto (SAGA), instituída em 2018, as ações de governo aberto no município, entre elas o processo de construção dos planos de ação.

O processo de construção dos planos de ação, como não poderia deixar de ser, é participativo. Como já mencionado, uma das diretrizes postas pela OGP é a instituição de um FGC para não só elaborar e conduzir o processo, como também atuar em sua implementação e avaliação.

Conforme narrado na Memória da iniciativa São Paulo Aberta (Prefeitura de São Paulo, 2016) e também no 1ํ Plano de Ação em Governo Aberto do município de São Paulo (OGP, 2016), o início do processo de construção se deu com a criação de uma comissão organizadora formada pela então Secretaria Municipal de Relações Internacionais (SMRI) e pela Controladoria Geral do Município (CGM), por meio da São Paulo Aberta e da Coordenadoria de Promoção da Integridade (COPI), respectivamente. A referida comissão elaborou questionários online e físicos a fim de diagnosticar o entendimento da população sobre os pilares de governo aberto como definidos pela OGP: transparência; participação cidadã; integridade (accountability) e inovação e tecnologia. 0 público-alvo da ação foram servidores públicos e participantes das oficinas do Programa Agentes de Governo Aberto4. No total, foram recebidas 429 contribuições.

Foi elaborado também formulário com questões específicas para entidades, organizações e movimentos sociais e populares mapeados pela comissão organizadora, que, de alguma forma, atuavam com governo aberto, resultando em 23 contribuições. Estes atores também participaram de encontros, nos quais foram comunicados e convidados a se envolver no processo de construção do plano de ação.

Posteriormente, foi publicado chamamento público no Diário Oficial da Cidade para selecionar entidades e organizações da sociedade civil interessadas em compor o FGC, instituído em setembro, quatro meses após a notificação da entrada de São Paulo no Programa Piloto para Governos Subnacionais. O FGC possuía a seguinte composição:

\footnotetext{
${ }^{4}$ Programa de formação da Secretaria do Governo Municipal e da Controladoria Geral do Município que visa à formação descentralizada de cidadãos sobre governo aberto.
} 
Tabela 1: Composição do Fórum de Gestão Compartilhada (2016)

\begin{tabular}{|l|l|}
\hline \multicolumn{1}{|c|}{ Governo } & \multicolumn{1}{|c|}{ Sociedade Civil } \\
\hline $\begin{array}{l}\text { Secretaria Municipal de Relações } \\
\text { Internacionais (representante do Comitê } \\
\text { Intersecretarial de Governo Aberto) }\end{array}$ & $\begin{array}{l}\text { Associação de Projetos Integrados e } \\
\text { Desenvolvimento Sustentável - PIDS-DRT } \\
\text { Laboratório Brasileiro de Cultura Digital } \\
\text { Liga Solidária } \\
\text { Movimento Popular de Saúde } \\
\text { Open Knowledge Brasil } \\
\text { Rede pela Transparência e Participação Social - } \\
\text { RETPS } \\
\text { Transparência Brasil } \\
\text { WRI Cidades Sustentáveis }\end{array}$ \\
\hline
\end{tabular}

Fonte: Elaborado pela autora com base no 1o Plano de Ação em Governo Aberto do município de São Paulo (2016).

As primeiras reuniões do FGC focaram na análise das contribuições obtidas por meio da aplicação dos questionários e, a partir dela, na elaboração da metodologia que seria empregada para a criação de três a cinco compromissos de governo aberto a serem assumidos e implementados pela Prefeitura em 2017. Cabe mencionar que a COPI/CGM, mesmo não fazendo parte do FGC, seguiu participando de todo o processo.

Ao fim do processo de análise das 429 contribuições obtidas pelos questionários de diagnóstico, o FGC chegou a nove eixos temáticos a serem trabalhados com o objetivo de avançar na agenda de governo no município: (i) participação; (ii) comunicação; (iii) conhecimento; (iv) institucionalização; (v) abertura de dados; (vi) uso de tecnologia livre; (vii) dados pessoais; (viii) apropriação de dados; e (ix) infraestrutura. Com esta sistematização e, dado o tempo exíguo, o FGC elaborou uma metodologia sucinta, com duas macro etapas, primando pela ampliação do envolvimento da sociedade civil no processo.

A primeira etapa compreendeu a realização de oficinas regionais e consulta pública. Assim, três oficinas regionais foram realizadas e mediadas pelo FGC na cidade de São Paulo em outubro, uma na zona leste, outra na zona oeste e a última no centro. Nestes encontros, após discussão, o público presente elegeu cinco dos nove eixos temáticos sistematizados pelo FGC a partir dos questionários de diagnóstico e, em um segundo momento, redigiu propostas de compromissos que visavam à superação de obstáculos relacionados a cada tema, sempre a partir da perspectiva de governo aberto.

Na consulta pública online, com o intuito de dar oportunidade de participação àqueles que não podiam comparecer às oficinas regionais, pôde-se também escolher cinco entre os nove temas prioritários e sugerir proposta de compromisso para cada um deles.

Os processos contaram com 106 participações, sendo 73 presenciais e 33 online. A fase presencial resultou em 12 propostas de compromissos e a online, em quatro, nos seguintes eixos temáticos: (i) Participação; (ii) Conhecimento; (iii) Comunicação; (iv) Institucionalização; e (v) Abertura de Dados e Tecnologia Livre.

A segunda etapa foi a submissão das propostas de compromisso para nova consulta pública online, na qual, por fim, o munícipe pôde eleger um compromisso por eixo. Os compromissos eleitos por 716 pessoas estão relacionados na tabela 2 . 
Tabela 2: Compromissos do $1^{\circ}$ Plano de Ação em Governo Aberto do Município de São Paulo

\begin{tabular}{|c|c|c|}
\hline Eixos Temáticos & Compromissos & Compromissos readequados $s^{3}$ \\
\hline (1) Participação & $\begin{array}{l}\text { Aumentar o poder de intervenção dos } \\
\text { Conselhos Participativos Municipais em } \\
\text { suas respectivas Subprefeituras, criando } \\
\text { sessões abertas deliberativas para } \\
\text { acolher as propostas e demandas dos } \\
\text { municipes. }\end{array}$ & $\begin{array}{l}\text { Aumentar o poder de intervenção dos } \\
\text { Conselhos Participativos Municipais em } \\
\text { suas respectivas Subprefeituras, criando } \\
\text { sessões abertas para acolher as } \\
\text { propostas e demandas dos munícipes. }\end{array}$ \\
\hline (2) Conhecimento & $\begin{array}{l}\text { Ampliar o Programa Agentes de Govemo } \\
\text { Aberto, enquanto programa permanente } \\
\text { de educação e cidadania, garantindo a } \\
\text { articulação territorial e a capilaridade } \\
\text { para alcançar o maior número de } \\
\text { pessoas. }\end{array}$ & \\
\hline (3) Comunicação & $\begin{array}{l}\text { Aumentar o uso de meios de } \\
\text { comunicação pela prefeitura, divulgando } \\
\text { as ações de governoaberto em jornais, } \\
\text { TVs, ônibus, equipamentos públicos, } \\
\text { mídias alternativas, em diálogo com o } \\
\text { legislativo, a fim de que esses meios } \\
\text { sejam lugares estratégicos de } \\
\text { comunicação permanente. }\end{array}$ & \\
\hline $\begin{array}{l}\text { (4) } \\
\text { Institucionalização }\end{array}$ & $\begin{array}{l}\text { Criar uma rede de servidores que } \\
\text { envolva todas as secretarias, entes e } \\
\text { equipamentos municipais, dialogando } \\
\text { com o Comitê Intersecretarial de } \\
\text { Governo Aberto dacidade de São Paulo } \\
\text { (CIGA-SP) e a SP Aberta. }\end{array}$ & \\
\hline $\begin{array}{l}\text { (5) Abertura de } \\
\text { Dadose Tecnologia } \\
\text { Livre }\end{array}$ & $\begin{array}{l}\text { Aperfeiçoar o LabProdam tornando-o } \\
\text { mais aberto, mapeando os grupos que já } \\
\text { trabalham com tecnologia livre, grupos } \\
\text { de jovens, stort ups e coletivos para criar } \\
\text { projetos tendo como referência o } \\
\text { Mobilab. }\end{array}$ & $\begin{array}{l}\text { Aperfeiçoar e fortalecer a atuação em } \\
\text { rede dos laboratórios e espaços de } \\
\text { inovação da PMSP, tais como o } \\
\text { Laboratório de Mobilidade Urbana de } \\
\text { São Paulo (MobiLab), o Pátio Digital } \\
\text { (SME) e o LabProdam tornando-os mais } \\
\text { abertos à participação social, à inovação } \\
\text { tecnológica e à utilização de dados } \\
\text { abertos, mapeando os grupos que já } \\
\text { trabalham com tecnologialivre (software } \\
\text { livre, princípios de dados abertos e } \\
\text { padrões da Web), grupos de jovens, stort } \\
\text { ups e coletivos para criar projetos de } \\
\text { governo aberto. }\end{array}$ \\
\hline
\end{tabular}

Fonte: Elaborada pela autora com base no 1o Plano de Ação em Governo Aberto do Município de São Paulo (2016).

Eleitos os cinco compromissos, o passo seguinte foi a definição das etapas/ações necessárias para efetivar a execução de cada um deles. Não havendo tempo hábil para discutir a definição de tais ações com a sociedade civil de forma mais ampla, com organizações ligadas às áreas relacionadas aos compromissos e com os cidadãos que participaram das oficinas e das consultas públicas, coube ao próprio FGC estabelecê-las.

Em 29 de novembro, no $1^{\circ}$ Encontro Brasileiro de Governo Aberto, realizado por organizações da sociedade civil e pela Prefeitura de São Paulo, por meio da atual Supervisão 
para Assuntos de Governo Aberto (SAGA) e da Coordenadoria de Promoção da Integridade (COPI), foram apresentados os compromissos eleitos e suas respectivas etapas de execução, com abertura à discussão sobre melhorias e processo de implementação, o qual começaria em 2017, em uma nova gestão, dado que o então prefeito Fernando Haddad não se reelegeu.

Por fim, os cinco compromissos do $1^{\circ}$ Plano de Ação em Governo Aberto foram incorporados ao Programa de Metas da gestão João Doria, correspondendo às linhas de ação 65.6 a 65.7 da meta 49 - projeto 65: São Paulo Aberta (Prefeitura de São Paulo, 2017).

\section{A Construção do Segundo Plano de Ação em Governo Aberto do}

\section{Município de São Paulo}

Como linhas de ação do Programa de Metas, a Prefeitura implementou, em 2017, o primeiro Plano de Ação e, em 2018, deu início às ações para a construção do segundo. Em um processo similar ao de 2016, por meio de chamamento público, foi instituída em 30 de maio a nova composição do FGC:

Tabela 3: Composição do Fórum de Gestão Compartilhada (2018)

\begin{tabular}{|l|l|ll|}
\hline \multicolumn{1}{|c|}{ Governo } & \multicolumn{1}{|c|}{ Sociedade Civil } & \multicolumn{1}{c|}{ Órgão de controle } \\
\hline Agente de Governo Aberto & Controladoria Geral do & \\
Associação de Projetos & Municipio & \\
Integrados e Desenvolvimento & Secretaria de Governo & \\
Sustentável - PIDS-DRT & Municipal & \\
Fundação Escola do Comércio - & Secretaria Municipal de Direitos & \\
Álvares Penteado & Humanos e Cidadania & Contas do \\
Instituto Update & Secretaria Municipal de Gestão & Tribunal de Municipio & \\
Movimento Cultural das & Secretaria Municipal de & \\
Periferias & Inovação e Tecnologia & \\
Rede pela Transparência e e & Secretaria Municipal de & \\
Participação Social - RETPS & Relações Intemacionais & \\
Transparência Brasil & Secretaria Municipal de & \\
WRI Cidades Sustentáveis & Urbanismo e Licenciamento & \\
\hline
\end{tabular}

Fonte: Elaborado pela autora com base no segundo plano de ação em Governo Aberto no município de São Paulo (2018). 
Após reuniões iniciais, nas quais se conciliou elaborar novamente um plano de ação com cinco compromissos, o grupo elaborou o seguinte fluxo metodológico:

- Definição dos temas (e levantamento de respectivos desafios) a serem abarcados pelo plano de ação;

- Realização de oficinas territoriais temáticas;

- Consulta pública para escolha dos compromissos;

- Definição das etapas de execução dos compromissos e atores responsáveis.

A primeira fase da metodologia se desdobrou em dois momentos: workshop e consulta pública online. Na primeira, mais de 60 participantes, entre representantes do governo e da sociedade civil, definiram os temas que embasariam a elaboração dos três primeiros compromissos: (i) Orçamento; (ii) Descentralização e Desenvolvimento Local; e (iii) Sistema de Informação, Comunicação Participativa e Transparência. Da consulta pública online aberta no mesmo mês, que teve 274 participações, vieram os temas: Educação e Orçamento. Importante mencionar que, em ambos os processos, os participantes também puderam apontar desafios relacionados às temáticas escolhidas.

Com os temas definidos e com amplo leque de desafios coletados, entrou-se na segunda fase, composta por oficinas regionais e nova consulta pública online. Foram realizadas dez oficinas regionais - denominadas neste novo contexto de oficinas territoriais temáticas -, nas quais foram elaboradas as propostas de compromissos. Ocorreram três oficinas na zona leste, duas na zona norte, duas na zona sul, duas no centro e uma na zona oeste. Para cada tema, foram realizadas duas oficinas e, de cada uma delas, saíram duas propostas de compromissos (figura 1).

Figura 1: Esquema de elaboração e definição dos compromissos do segundo plano de ação em Governo Aberto

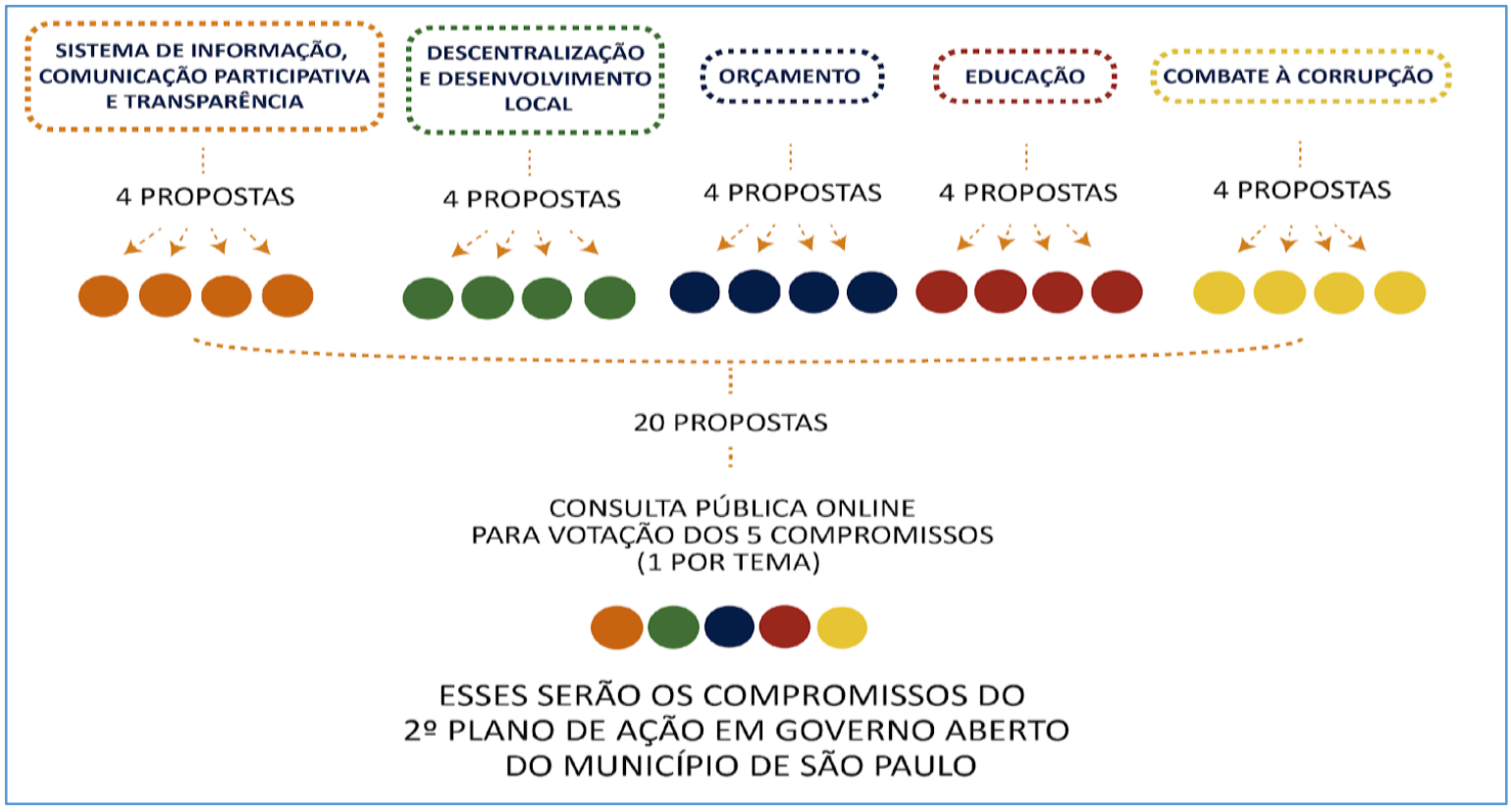

Fonte: SGM / Governo Aberto na Cidade de São Paulo, 2018. 
Conforme apresentado na figura 1 , as propostas de compromissos foram submetidas à nova consulta pública online, na qual o cidadão pôde escolher uma entre as quatro propostas de compromissos para cada tema - uma etapa presencial da consulta pública foi realizada no centro de São Paulo. Assim, no final do mês de outubro, 2.279 cidadãos elegeram os compromissos que comporiam o segundo Plano de Ação do município de São Paulo, transcritos na tabela 4.

Tabela 4 - Compromissos do $2^{\circ}$ Plano de Ação em Governo Aberto do Município de São Paulo eleitos em consulta pública e readequados por equipe técnica

\begin{tabular}{|c|c|c|}
\hline Tema & Compromisso eleito & Compromisso readequado por equipe técnica \\
\hline (1) Orçamento & $\begin{array}{l}\text { Institucionalizar o orçamento participativo, por meio do Conselho Participativo } \\
\text { Municipal e da sociedade civil, nas } 32 \text { Subprefeituras, criando regras e } \\
\text { procedimentos a serem seguidos pelos subprefeitos, incluindo: boletim } \\
\text { informativo (impresso e virtual) e site, com linguagem amigável/cidadã, sobre o } \\
\text { gasto executado e proposto por setor e projeto; criação de cadastro público de } \\
\text { organizações e cidadãos para divulgação de informações; divulgação ampla e } \\
\text { prévia das ações e discussões de orçamento participativo. }\end{array}$ & \\
\hline $\begin{array}{l}\text { (2) } \\
\text { Descentralização e } \\
\text { Desenvolvimento } \\
\text { local }\end{array}$ & $\begin{array}{l}\text { Vincular os gastos públicos aos planos de ação desenvolvidos através de } \\
\text { participação social, discutindo e deliberando coletivamente sobre as demandas } \\
\text { territoriais, respeitando os conselhos municipais, agentes e usuários de } \\
\text { equipamentos públicos e outras instâncias participativas locais, bem como } \\
\text { garantindo a publicidade e acessibilidade do orçamento público de forma } \\
\text { regionalizada e por equipamento. }\end{array}$ & $\begin{array}{l}\text { Nos gastos públicos, priorizar planos de ação } \\
\text { desenvolvidos através de participação social, } \\
\text { discutindo e deliberando coletivamente } \\
\text { sobre as demandas territoriais, respeitando } \\
\text { os conselhos municipais, agentes e usuários } \\
\text { de equipamentos públicos e outras } \\
\text { instâncias participativas locais, bem como } \\
\text { garantindo a publicidade acessibilidade do } \\
\text { orçamento público de forma regionalizada e } \\
\text { por equipamento. }\end{array}$ \\
\hline $\begin{array}{l}\text { (3) Sistema de } \\
\text { Informação, } \\
\text { Comunicação } \\
\text { Participativa }\end{array}$ & \begin{tabular}{|l|} 
Desenvolver a integração entre o Diário Oficial, Portal da Transparência e o \\
Sistema Orçamentário Financeiro (SOF), com linguagem e interfaces \\
participativas, visando à acessibilidade, por meio de comunicação digital e \\
física (site, clipping, mensagens, publicações), por meio de pontos focais da \\
Rede INFOAberta e agentes da sociedade civil organizada para disseminar, \\
difundir e formar a sociedade civil e servidores públicos nesses sistemas. \\
\end{tabular} & \\
\hline (4) Educação & $\begin{array}{l}\text { Incluir no Projeto Político Pedagógico um processo de cocriação de atividades } \\
\text { culturais e de letramento de cidadania no território e entorno da escola, com o } \\
\text { envolvimento da comunidade escolar (APM, pais, direção, professores, alunos e } \\
\text { funcionários), fazer valer a Portaria } 6771 / 2013 \text { da SME, tornando-o público, visivel } \\
\text { e também viabilizar uma agenda física e online aberta, que organize e } \\
\text { disponibilize o uso dos espaços públicos escolares e culturais do território, e } \\
\text { efetivar a prestação de contas das atividades realizadas no final do ano letivo } \\
\text { (online, impressos e cartazes). }\end{array}$ & $\begin{array}{l}\text { Maior transparência, tecnologia e inovação } \\
\text { para que a comunidade educativa } \\
\text { (educadores, gestores, alunos, familias e } \\
\text { sociedade civil) possa acompanhar a } \\
\text { execução dos recursos das Unidades } \\
\text { Educacionais (UEs) e participar das decisões } \\
\text { sobre a alocação dos investimentos. }\end{array}$ \\
\hline $\begin{array}{l}\text { (5) Combate à } \\
\text { Corrupção }\end{array}$ & \begin{tabular}{|l|} 
Institucionalizar que os processos licitatórios tenham fiscalização cidadã, \\
através de agentes da sociedade civil com atuação na respectiva temática / área \\
comprovada e vínculo com o respectivo território, cuja seleção se dará por \\
sorteio e de forma rotativa, garantindo acessibilidade dos dados públicos de \\
forma aberta por meio da integração entre os sistemas de contratos e licitações \\
e Sistema Orçamentário Financeiro da Prefeitura do Município de São Paulo.
\end{tabular} & $\begin{array}{l}\text { Garantir a acessibilidade dos dados públicos } \\
\text { de forma aberta, por meio de integração e } \\
\text { qualificação de informações disponibilizadas } \\
\text { sobre contratos, licitações e execução } \\
\text { orçamentária / financeira do municipio de } \\
\text { São Paulo, aprimorando os mecanismos já } \\
\text { existentes, possibilitando melhores } \\
\text { condições para a fiscalização cidadã dos } \\
\text { processos licitatórios }\end{array}$ \\
\hline
\end{tabular}

Fonte: Elaborado pela autora com base no segundo plano de ação em Governo Aberto (2019).

Após a eleição, foram realizadas reuniões técnicas nas quais foram discutidas as viabilidades de execução dos compromissos com base em pareceres técnicos e jurídicos emitidos pelas secretarias envolvidas. Os textos dos compromissos de Descentralização e Desenvolvimento Local, Educação e Combate à Corrupção, conforme tabela 4, foram alterados. $\mathrm{Na}$ ocasião, foram definidas as etapas de execução e os atores responsáveis, validadas, posteriormente, pelo FGC, cujas representações da sociedade civil também se implicaram como atores responsáveis pela implementação.

Em maio, a Prefeitura de São Paulo alterou, pela segunda vez, a redação e algumas etapas de execução dos compromissos de Orçamento e Descentralização e Desenvolvimento Local; e, em junho, com a assinatura do prefeito, reenviou o $2^{\circ}$ Plano de Ação à OGP, nas versões em inglês e em português. Segue, na Tabela 5, resumo da redação final dos compromissos mencionados: 
Tabela 5: Compromissos do segundo plano de ação em Governo Aberto, alterados pela Prefeitura de São Paulo

\begin{tabular}{|l|l|}
\hline \multicolumn{1}{|c|}{ Tema } & \multicolumn{1}{c|}{ Compromisso eleito } \\
\hline (1) Orçamento & $\begin{array}{l}\text { Disponibilizar instrumentos de transparência da gestão fiscal, } \\
\text { dando ampla divulgação, inclusive por meios eletrônicos de } \\
\text { acesso público: aos planos, orçamentos e leis de diretrizes } \\
\text { orçamentárias; às prestações de contas e o respectivo parecer; e } \\
\text { aos relatórios de gestão fiscal. }\end{array}$ \\
\hline $\begin{array}{l}\text { (2) Descentralizaçãoe } \\
\text { Desenvolvimento local }\end{array}$ & $\begin{array}{l}\text { Elaborar os Planos de Ação das Subprefeituras, ouvindo as } \\
\text { demandas territoriais, os conselhos municipais, agentes e } \\
\text { usuários de equipamentos públicos e outras instâncias } \\
\text { participativas locais, assim como garantindo a publicidade e } \\
\text { acessibilidade do orçamento público. }\end{array}$ \\
\hline
\end{tabular}

Fonte: Elaborado pela autora com base no segundo plano de ação em Governo Aberto (2019).

Com a repactuação do Programa de Metas para o biênio 2019-2020 anunciada pela Prefeitura de São Paulo em abril, a implementação dos compromissos do $2^{\circ}$ Plano de Ação tornou-se a meta 34.1 do Objetivo Estratégico 34 (SÃO PAULO, 2019).

\section{O Amadurecimento do Processo de Construção dos Planos de Ação}

A experiência do processo de construção do Plano de Ação em Governo Aberto da cidade de São Paulo a partir do Programa Piloto para Governos Subnacionais - um projeto sem precedentes no mundo - gerou aprendizados que resultaram em um amadurecimento da elaboração do $2^{\circ}$ Plano de Ação, fato que se refletiu no teor dos compromissos apresentados.

0 primeiro ponto a ser destacado é a ampliação do FGC que passou de nove para dezoito cadeiras. Na primeira composição, apenas a Secretaria Municipal de Relações Internacionais, coordenadora do Comitê Intersecretarial de Governo Aberto da Cidade de São Paulo (CIGA-SP), representava o governo. Por uma demanda trazida pelos atores da sociedade civil, outras secretarias do CIGA-SP passaram a compor o colegiado, constituindo um órgão paritário. Cinco organizações da sociedade civil da composição de 2016 se mantiveram na composição de 2018, o que pode ser considerado positivo, devido ao acúmulo de conhecimento que esses atores possuem acerca de governo aberto e do processo anterior.

Um segundo ponto de destaque foi a ampliação do número de oficinas territoriais temáticas realizadas para a elaboração de propostas dos compromissos, que passou de três para dez. Nas dez oficinas realizadas em 2018, houve 155 participações, 82 a mais em relação às obtidas nas três oficinas realizadas em 2016, porém, proporcionalmente, as oficinas de 2016 tiveram maior 
público. Já nas duas consultas públicas online de 2018, foram 3.028 contribuições, enquanto, em 2016, também em dois processos, foram 749 contribuições.

A cidade de São Paulo possui 12 milhões de habitantes (IBGE, 2019). Tal contingente populacional desafia a implementação de qualquer modelo de instância participativa que vise uma real representatividade da ampla diversidade do município. 0 relatório emitido pelo Mecanismo Independente de Avaliação (IRM, da sigla em inglês para Independent Reporting Mechanism) sobre a construção do $1^{\circ}$ Plano de Ação considerou o processo, de fato, participativo. Os números de 2018, por serem mais expressivos, provavelmente, gerarão outra avaliação positiva com relação à participação social no processo. Porém, representam uma parcela muito pequena da população paulistana.

Ainda sobre as oficinas territoriais temáticas, diferentemente de 2016, a SAGA mapeou servidores técnicos das secretarias cujas atribuições iam ao encontro dos temas definidos e os convidou a participar das oficinas, como uma maneira de tentar assegurar que os compromissos construídos fossem exequíveis e consoantes aos trabalhos realizados pela Prefeitura, mas a adesão foi baixíssima. No workshop que deu início ao processo, realizado no centro de São Paulo e em horário comercial, a presença de servidores, inclusive secretários municipais, foi significativa. Das cerca de 60 participações ao longo de um dia inteiro de atividades, os servidores públicos representaram uma pequena maioria nos dois períodos. 0 horário e a localização do workshop, bem como a presença de secretários, talvez justifiquem uma maior presença desses profissionais. Por sua vez, oito das dez oficinas territoriais temáticas foram realizadas em territórios afastados do centro, cinco delas no período noturno e duas aos sábados, fatores que possibilitaram maior participação da sociedade civil.

\section{Os Aspectos Positivos e Negativos do Processo de Criação dos Planos de Ação}

No item anterior foram destacados alguns aspectos positivos da criação do segundo Plano de Ação em comparação com o primeiro processo, como a inclusão de mais secretarias no FGC e, consequentemente, maior participação destas nas oficinas territoriais temáticas realizadas em maior número (em dez territórios distintos).

Ao fazer um comparativo acerca dos processos de construção dos planos de ação de 2016 e 2018 e especular o quanto cada um definiu o teor geral dos compromissos até abrindo brechas para intervenção por parte da Prefeitura, pode-se dizer que o bojo dos compromissos do $1^{\circ}$ Plano de Ação se resume a ações que objetivaram trazer maior conhecimento em relação à pauta de governo aberto e aos pilares que a permeiam, tanto para dentro, quanto para fora da Prefeitura.

As oficinas foram mediadas por membros do próprio FGC, que, por esta razão, não puderam participar ativamente das discussões que antecipavam a escolha dos temas e a redação das propostas de compromisso. À vista disso, em 2018, foram contratados mediadores externos para 
que os membros do FGC pudessem participar mais ativamente das atividades. Diferentemente de 2016, quando o processo se deu sem nenhum tipo de recurso financeiro, tal contratação pôde ser viabilizada, pois o grupo que constitui as entidades da sociedade civil membras do FGC recebeu financiamento do Banco Mundial para subsidiar o processo de construção. Com este aporte, além de dois mediadores, foram contratados profissionais para divulgar a consulta pública final, inclusive, utilizando-se de estratégias de impulsionamento ao Facebook, e para construir o site do FGC (que seguia desatualizado até o momento desta pesquisa). Apesar do incremento da participação social, presume-se que os desacordos (ou acordos tardios) dos atores da sociedade civil do FGC sobre a melhor forma de utilizar o recurso contribuíram para minimizar o impacto que o fundo poderia ter trazido ao processo.

É presumível também que uma participação mais efetiva de membros do FGC, sobretudo da sociedade civil, tenha resultado em compromissos que, em uma primeira análise, demandam mais esforços da Prefeitura. Para Cruz-Rubio (2015), ações que incluam os valores e princípios de governo aberto são passíveis de enquadramento em duas modalidades não excludentes entre si: políticas públicas para governo aberto e políticas públicas abertas. Por esse viés, pode-se dizer que os compromissos do $1^{\circ}$ Plano de Ação se caracterizam como políticas da primeira modalidade, e do $2^{\circ}$ Plano de Ação, da segunda modalidade:

Na primeira modalidade, o governo aberto é o fim visado, que se destina a incluir, fortalecer ou desenvolver de forma substantiva algum ou vários dos seus fatores. [...] Na segunda modalidade, o governo aberto (e seus valores) se constitui num meio privilegiado cujos princípios (re)orientam e a conformação, desenvolvimento e/ou (re)desenho das políticas públicas (CRUZ-RUBIO, 2015, p.139).

Embora mais exigentes comparados aos de 2016, os novos compromissos não se adequaram totalmente às recomendações da OGP quanto à clareza, especificidade e objetividade das ações, talvez um reflexo da falta de alinhamento do próprio FGC, sobretudo, por resistência de algumas representações da sociedade civil que, privadas de espaços efetivos de participação, se posicionaram de forma a não apenas propor o que a Prefeitura "deve" fazer, mas também o "como" fazer. Vide o texto do compromisso 3, por exemplo, (praticamente um parágrafo) o único que não foi modificado:

Desenvolver a integração entre o Diário Oficial, Portal da Transparência e o Sistema Orçamentário Financeiro (SOF), com linguagem e interfaces com o público, visando a acessibilidade, por meio de comunicação digital e física (site, clipping, mensagens, publicações), através dos pontos focais da Rede INFOAberta e agentes da sociedade civil organizada para disseminar, difundir e formar a sociedade civil e servidores públicos nesses sistemas (Prefeitura de São Paulo, 2018).

Trata-se de um compromisso que, em uma análise possível, se decompõe em três partes: (i) a integração de sistemas; (ii) a sua comunicação por meio de materiais impressos e digitais; (iii) organização de processos formativos sobre o sistema. A integração dos sistemas apontados é, em suma, o compromisso. As demais ações podem ser entendidas como etapas de execução.

Como já pontuado, o intuito de mapear e convidar servidores técnicos para participarem das oficinas era de que estes pudessem atuar como moderadores internos das discussões, prezando pela construção de propostas de compromissos factíveis a fim de não recair em 
equívocos do ponto de vista técnico e jurídico cometidos no processo de 2016 e que comprometeram a efetividade da implementação do $1^{\circ}$ Plano de Ação. Neste ponto, cabe mencionar que, assim como em 2016, o FGC estabeleceu que as propostas de compromissos vindas das oficinas e eleitas em consulta pública não seriam alteradas posteriormente, como uma forma de não deslegitimar o processo participativo.

No entanto, apesar do acordo, como se pode observar nas tabelas quatro e cinco, modificações foram feitas, e de forma mais expressiva em comparação ao $1^{\circ}$ Plano de Ação, que teve duas alterações (compromissos 1 e 5). No total, sem mencionar as alterações nas etapas de execução, o $2^{\circ}$ Plano de Ação passou por cinco modificações, as três primeiras (tabela 4) motivadas e justificadas pela emissão de pareceres técnicos e jurídicos e as duas últimas (tabela 5) por diretrizes dos gabinetes responsáveis pela execução dos compromissos.

Outra pressuposição é a de que as alterações nas redações poderiam ter sido minimizadas ou até mesmo não necessárias caso as oficinas territoriais temáticas tivessem adesão por parte dos técnicos convidados, para além daqueles que compõem o FGC e/ou atuavam na SAGA. Submeter as vinte propostas de compromissos derivados das oficinas à análise técnica e jurídica e ao crivo do gabinete do prefeito antes da consulta pública possivelmente também descartaria alterações futuras. Rever o acordo de que as propostas de compromissos, uma vez saídas das oficinas, não podem ser alteradas é uma ação prudente já que não foi mantido em nenhum dos processos.

A metodologia de construção do $1^{\circ}$ Plano de Ação, sobretudo por seu enfoque participativo, foi bem avaliado e elogiado pela OGP, e a expectativa é que o processo de 2018 também o seja, mas a efetividade dessa participação torna-se questionável quando a Prefeitura, apesar do cuidado em preservar a demanda inicial, altera os compromissos pretendidos pela população, colocando em dúvida a sua adesão a uma pauta que tem a participação e a transparência como pilares.

Diante do exposto, havendo a construção de um terceiro plano de ação, convém realizar não apenas um trabalho de aprimoramento metodológico que tenha aprovação prévia da alta gestão municipal, mas também um trabalho de sensibilização da mesma quanto à agenda de governo aberto.

\section{À Guisa de Conclusão...}

Ações desenvolvidas pela Prefeitura de São Paulo nos pilares de Governo Aberto, visando maior transparência, controle social e aproximação entre os munícipes e a Prefeitura levaram o município a fazer parte do programa piloto para governos locais, lançado pela Parceria para Governo Aberto (OGP), em 2016, desenvolvendo, desde então, planos de ação periódicos. Apesar do pioneirismo, tanto do programa, quanto da participação, São Paulo se destacou no processo de construção do então $1^{\circ}$ Plano de Ação em Governo Aberto, finalizado em dezembro do mesmo ano. 
Os compromissos do $1^{\circ}$ Plano de Ação em Governo Aberto do Município de São Paulo giraram em torno da disseminação e institucionalização da própria pauta. Estes foram assumidos pela então Secretaria Municipal de Relações Internacionais (a quem pertencia a pauta) e pela Controladoria Geral do Município, reflexo da metodologia adotada que, por não envolver as secretarias potencialmente executantes e/ou parceiras no processo, não as fez se sentirem responsáveis por assumir as ações.

Por essa razão, em 2018, buscou-se envolver as secretarias desde o começo do processo de construção do $2^{\circ}$ Plano de Ação, isso, somado a uma maior atuação das representações da sociedade civil nas oficinas territoriais temáticas, resultou na elaboração de compromissos mais relevantes, mas que também transparecem a necessidade de ajustes na metodologia adotada e a falta de alinhamento entre os atores envolvidos no processo.

No entanto, apesar das incongruências observadas, houve um salto qualitativo do processo de construção de 2016 para 2018, sobretudo, no que se refere às ações de incentivo à participação das secretarias e à abertura à participação da sociedade civil. 


\section{Referências Bibliográficas}

Bellix, Laila., \& Guimarães, Caroline Burle S., \& Machado, Jorge. (2016). Qual conceito de Governo Aberto? Uma aproximação aos seus princípios. Documentado apresentado no VII Congreso Internacional en Gobierno, Administración e Políticas Públicas. Acessado em 19 de Abril de 2019, de: $\quad$ http://www.gigapp.org/index.php/mis-publicacionesgigapp/publication/show/2494

Calderón, Cesar., \& Lorenzo, Sebastián. (2010). Gobierno Abierto. Ed. Algon Editores: México. Acessado em 10 de Maio de 2019, de: https://issuu.com/sanluisparticipa/docs/gobierno abierto - c sar calder n

Cruz-Rubio, César Nicandro. (2016). O que é (e o que não é) governo aberto? Rev. Temas de Administração Pública. Acessado em 19 de Abril de 2019, de: https://periodicos.fclar.unesp.br/temasadm/article/view/8583

Gil, Antonio Carlos. (2008). Métodos e técnicas de pesquisa social. 6o ed. São Paulo: Ed. Atlas. Acessado em 07 de Junho de 2019, de: http://197.249.65.74:8080/biblioteca/bitstream/123456789/707/1/M\%C3\%A9todos\%20 de\%20Pesquisa\%20Social.pdf

Instituto Brasileiro de Geografia e Estatística. (2017). Cidades. São Paulo - SP. Acessado em 07 de Junho de 2019, de: https://cidades.ibge.gov.br/brasil/sp/sao-paulo/panorama

Mecanismo de Avaliação Independente. (2017). Análise Preliminar 2017: São Paulo. Acessado em 10 de Maio de 2019, de: http://www.opengovpartnership.org/sites/default/files/SaoPaulo IRM-Preliminary-Review 2017 for-public-comment.pdf

Open Government Partnership. (2011). Declaração sobre Governo Aberto. Acessado em 10 de Maio de 2019, de: http://www.itamaraty.gov.br/sala-de-imprensa/notas-aimprensa/declaracao-por-ocasiao-dolancamento-da-201cparceria-para-governo-aberto201d

Open Government Partnership. (2016). Declaração Subnacional de Governo Aberto. Acessado em 10 de Maio de 2019, de: http://www.opengovpartnership.org/sites/default/files/OGP subnationaldeclaration EN.pdf

Open Government Partnership. (2019). Informação institucional. Acessado em 06 de Junho de 2019, de: https://www.opengovpartnership.org/about/approach/

São Paulo, Prefeitura Municipal de. (2016a). Memória da Iniciativa São Paulo Aberta. São Paulo: Imprensa Oficial do Estado.

São Paulo, Prefeitura Municipal de. (2016b). Plano de Ação da cidade de São Paulo. Acessado em 20 de Maio de 2019, de: http://www.opengovpartnership.org/sites/default/files/SaoPaulo IRM-Preliminary-Review 2017 for-public-comment.pdf

São Paulo, Prefeitura Municipal de. (2018). 2º Plano de Ação em Governo Aberto do Município de São Paulo. Acessado em 08 de Junho de 2019, de: http://liveogp.pantheonsite.io/sites/default/files/Sao-Paulo IRM-Preliminary-Review 2017 for-publiccomment.pdf

São Paulo, Prefeitura Municipal de. (2017). Programa de Metas 2017| 2020. Acessado em 01 de Junho de 2019, de: http://programademetas.prefeitura.sp.gov.br/homeAntiga 
São Paulo, Prefeitura Municipal de. (2019). Programa de Metas 2019| 2020. Acessado em 01 de Junho de 2019 , de: http://programademetas.prefeitura.sp.gov.br/assets/up/Programa\%20Metas\%2020192020 texto.pdf

U.S. Government. Transparency and open government: memorandum for the heads of executive departments and agencies, 2009. Acessado em 09 de Maio de 2019, de: https://obamawhitehouse.archives.gov/the-press-office/transparency-and-opengovernment 